\title{
microRNA-mediated regulation of innate immune response in rheumatic diseases
}

\author{
Xiaobing Luo ${ }^{1,2}$, Koustubh Ranade ${ }^{2}$, Ronel Talker ${ }^{3}$, Bahija Jallal ${ }^{2}$, Nan Shen ${ }^{* 1}$ and Yihong Ya**2
}

\begin{abstract}
miRNAs have been shown to play essential regulatory roles in the innate immune system. They function at multiple levels to shape the innate immune response and maintain homeostasis by direct suppression of the expression of their target proteins, preferentially crucial signaling components and transcription factors. Studies in humans and in disease models have revealed that dysregulation of several miRNAs such as miR-146a and miR-155 in rheumatic diseases leads to aberrant production of and/or signaling by inflammatory cytokines and, thus, critically contributes to disease pathogenesis. In addition, the recent description of the role of certain extracellular miRNAs as innate immune agonist to induce inflammatory response would have direct relevance to rheumatic diseases.
\end{abstract}

\section{Introduction}

miRNAs are small endogenous noncoding RNAs, discovered nearly two decades ago. Our understanding of the biological importance of miRNAs has grown exponentially recently owing to the tremendous breakthrough in research in the last several years. Mature miRNAs exhibit robust regulatory roles in almost all biological processes by modulating the expression of their target genes. Not surprisingly, emerging studies have demonstrated the active role of miRNAs in regulating the development and function of immune cells and the association of aberrant expression of miRNA with disorders of the immune system. In this review, we will first discuss several noteworthy features and new findings in biology of miRNA, then focus on the function of

\footnotetext{
*Correspondence: nanshensibs@gmail.com, YaoY@medimmune.com 'Joint Molecular Rheumatology Laboratory of Institute of Health Sciences and Shanghai Renji Hospital, Shanghai JiaoTong University School of Medicine and Shanghai Institutes for Biological Sciences, Chinese Academy of Sciences, 145 Shan Dong Middle Road, Shanghai 200001, China

2Medlmmune, One Medlmmune Way, Gaithersburg, MD 20878, USA

Full list of author information is available at the end of the article
}

miRNA in regulating innate immune response, and, finally, touch the evidence of dysregulation of this process in connection with rheumatic diseases.

\section{New findings in miRNA biology miRNA biogenesis and action processes are subject to dynamic regulation}

miRNA genes are prevalent in multicellular organisms. These genes often form clusters encoding multiple mature miRNAs that cooperatively regulate the same mRNA target or functionally related targets [1]. Most miRNAs are transcribed by RNA polymerase II. The cell type-specific or spatiotemporal expression patterns of miRNAs are primarily determined at the transcriptional level [2]. The primary transcripts of miRNA genes are sequentially processed by two nucleases, Drosha and Dicer, whose activities are assisted by a number of other protein cofactors, to generate the $\sim 22$ nucleotide-long miRNA duplexes [1]. Regulation of the expression and activity of these miRNA processors during different developmental stages or in response to environmental stimuli thus represents an intriguing post-transcriptional control of the miRNA expression profile that accommodates the needs of shaping protein expression in a given cell [2]. For instance, activation of the mitogen-activated protein kinase/extracellular signal-regulated kinase signaling pathway mediates phosphorylation of a critical partner of Dicer, TRBP, which leads to increased stability of the processing complex and enhanced miRNA production [3]: a component of the processing complexes that regulates the biogenesis of a subset of miRNAs is the $\mathrm{KH}$ type splicing regulatory protein (KSRP) [4]; the activity of KSRP can be induced by signaling in an innate immune system [5,6]. Once cleaved, the guide strand of the miRNA duplex gives rise to mature miRNA, which is preferentially incorporated into the RNA-induced silencing complex (RISC) and guides the complex to its target mRNAs. The passenger strand of the miRNA duplex gives rise to the rarely expressed star-form miRNA (miRNA*); however, the ratio of miRNA to miRNA* can be dynamically controlled in response to stimuli. miRNA* species also exhibit important regulatory function $[6,7]$. In most cases, the miRNA:target interaction is primarily 
mediated by base-pairing of the miRNA seed region (nucleotides 2 to 7) to the 3' UTR of the mRNA, resulting in target degradation and/or translational repression [1]. Such a short sequence signature of individual miRNAs is readily found in the genomic transcripts, endowing them with the potential to target dozens or even hundreds of different mRNAs. Moreover, multiple miRNAs can bind to the same mRNA and coordinate its expression [2]. In addition, several other features affect miRNA:target interaction, including local AU content, the position of the binding site in the 3' UTR, and pairing at the 3' end of miRNA [8].

Similar to manipulation of miRNA biogenesis by regulating the components of the processing complex, miRNA effects can be enhanced or attenuated by positively or negatively regulating the levels and activity of RISC components [2]. For instance, in response to stress, the mitogen-activated protein kinase/p38 kinase signaling pathway mediates phosphorylation of serine-387 in AGO2, the core component of RISC, increasing its recruitment to processing bodies [9]. Another intriguing regulation of miRNA function on specific mRNAs depends on the interplay between RISC and other RNA binding proteins. The AU-rich element binding protein $\mathrm{HuR}$ is required by let-7/RISC for efficient inhibition of c-Myc expression [10], whereas in other stress conditions HuR relieves miR-122-mediated repression of CAT-1 mRNA by promoting dissociation of RISC from the target RNA [2,11]. The released mRNA is recruited to polysomes for active translation, suggesting miRNAmediated repression is reversible [11].

\section{Mature miRNA polymorphisms}

A great number of polymorphisms other than those transcribed from genetic variants have been identified in mature miRNA species [12]. First, Drosha and Dicer cleavage of some precursor molecules is not uniform and yields miRNA isoforms with shifting termini [2]. Second, the double-stranded segments in many miRNA precursor molecules are subject to RNA editing (adenosine to inosine) by adenosine deaminases that act on RNA. Those that occur in the mature miRNA corresponding region alter the sequence of the final miRNA product $[12,13]$. RNA editing may also affect protein binding and, thus, alter the processing efficiency or nuclear export of miRNA precursors [13]. Third, deep sequencing has revealed an abundance of untemplated additions of adenosine or uracil residues to the 3 ' end of miRNAs [12]. Such polymorphisms can greatly affect the stability of mature miRNAs, and may direct the miRNA to different target mRNAs if located in the seed region [2]. New technologies, such as deep sequencing, will promote the identification of functional isoforms originating from a given miRNA gene and that precise quantification of their expression levels in both physiological and disease settings.

\section{Expanding the rules of miRNA behavior}

Deep sequencing also revealed numerous miRNA binding sites that reside in coding sequences [14], in line with previous sporadic reports of functional miRNA target sites within the protein-coding region $[15,16]$. miRNA targeting can also be mediated by 11 to 12 contiguous perfect match to the center of the miRNA [17]. There are also reports on miRNAs functioning as activators of translation $[18,19]$. In a recent study, a role for miR-328 as an RNA decoy to directly bind hnRNP E2 was ascribed, thus interrupting the protein's binding capacity and regulatory function towards select mRNAs [20]. Interaction between miRNAs and long noncoding RNAs or transcribed pseudogenes has also been reported $[21,22]$; such transcripts, along with mRNAs [23,24], can reciprocally control the level and function of miRNAs by dynamic binding to the same miRNA [25]. A growing body of evidence also shows the existence of miRNAs in body fluids, which may be transferable and functional in recipient cells [26,27]. However, more studies are warranted to fully understand the miRNA regulatory network in maintaining homeostasis and the implication in human diseases.

\section{Regulation of innate immune response by miRNAs}

Since the initial observation of distinct miRNA expression patterns across the hematopoietic lineage [28], extensive studies have established critical roles for specific miRNAs in immune cell development and, equally importantly, in regulating their function during both innate and adaptive immune response [29-31]. Particularly, cells of the innate immune branch, such as monocyte/ macrophages, dendritic cells (DCs), and granulocytes, constitute the first line of defense against invading pathogens. Toll-like receptors (TLRs), which constitute the major pathogen detection system, initiate rapid signaling upon engagement in innate immune cells to induce the transcription of a set of inflammatory cytokines, such as TNF $\alpha$ and type I interferons, and to subsequently prime specific adaptive immune responses. Engagement of other pattern-recognition receptors such as nucleotide-binding oligomerization domain-like receptors (NLRs) and subsequent inflammasome assembly leads to caspase- 1 activation and, hence, the production of IL-1 $\beta$ and IL-18 to mediate inflammatory response. Discoveries of novel miRNA players in regulation of innate immunity continue to emerge (Table 1).

\section{miRNA regulates innate immune cell development}

A circuitry involving mutual repression between three miRNAs and a key protein regulator has been described 
Table 1. miRNA players in regulation of innate immunity

\begin{tabular}{|c|c|c|c|c|c|c|c|}
\hline \multirow[b]{2}{*}{ miRNA } & \multicolumn{5}{|c|}{ Target } & \multirow[b]{2}{*}{ Regulated process } & \multirow[b]{2}{*}{ References } \\
\hline & $\begin{array}{l}\text { Ligand/ } \\
\text { cytokine }\end{array}$ & Receptor & $\begin{array}{l}\text { Signaling } \\
\text { component }\end{array}$ & $\begin{array}{l}\text { Transcription } \\
\text { factor }\end{array}$ & Others & & \\
\hline let-7e & & TLR4 & & & & Endotoxin sensitivity and tolerance & [53] \\
\hline miR-106a & IL-10 & & & AML1 & & Monocyte differentiation, IL-10 production & {$[32,77]$} \\
\hline miR-125b & TNFa & & & & & TNFa production by macrophages & [55] \\
\hline miR-142-3p & IL-6 & & & & & IL-6 production by DCs & [76] \\
\hline miR-145 & & & MAL & & & TLR2-mediated and TLR4-mediated signaling & [63] \\
\hline miR-146a & & & $\begin{array}{l}\text { IRAK1, IRAK2, } \\
\text { TRAF6 }\end{array}$ & IRF5, STAT1 & & $\begin{array}{l}\text { NF-kB-mediated inflammatory response, type I } \\
\text { interferon induction and signaling }\end{array}$ & $\begin{array}{c}{[39-41,43,} \\
44,47]\end{array}$ \\
\hline miR-148a/b & & & CaMKIlla & & & DC activation/antigen presentation & [66] \\
\hline miR-15 & & & $\mathrm{IKKa}$ & & & Monocyte differentiation & [34] \\
\hline $\operatorname{miR}-152$ & & & CaMKIlla & & & DC activation/antigen presentation & [66] \\
\hline \multirow[t]{2}{*}{ miR-155 } & & & $\begin{array}{l}\text { IKKE MyD88 } \\
\text { TAB2 }\end{array}$ & $\begin{array}{l}\text { PU.1, C/EBPß, } \\
\text { c-Fos }\end{array}$ & $\begin{array}{l}\text { KPC1 SOCS1 } \\
\text { SHIP1 }\end{array}$ & $\begin{array}{l}\text { DC development/maturation granulocyte/ } \\
\text { monocyte expansion endotoxin sensitivity } \\
\text { and tolerance }\end{array}$ & $\begin{array}{l}{[6,38,45} \\
50-60,92]\end{array}$ \\
\hline & & & & $\mathrm{BCL6}$ & & $\begin{array}{l}\text { NF-KB-mediated inflammatory response, AKT } \\
\text { signaling and inflammation, type I interferon } \\
\text { induction and signaling }\end{array}$ & \\
\hline $\operatorname{miR}-155^{*}$ & & & & & IRAKM & Type I interferon induction & [6] \\
\hline miR-16 & & & $\mathrm{IKKa}$ & & & Monocyte differentiation & [34] \\
\hline miR-17-5p & & & & AML1 & & Monocyte differentiation & [32] \\
\hline miR-187 & & & & $\mid \kappa B \zeta$ & & IL-10-driven anti-inflammatory response & [71] \\
\hline miR-19a/b & & TLR2 & & & & TLR2-triggered inflammatory response & [73] \\
\hline $\mathrm{miR}-200 \mathrm{~b} / \mathrm{c}$ & & & MyD88 & & & NF-kB-mediated inflammatory response & [65] \\
\hline miR-20a & & & & AML1 & & Monocyte differentiation & [32] \\
\hline miR-21 & JAG1 & & & & PDCD4 & $\begin{array}{l}\text { DC development/maturation, NF-KB-mediated } \\
\text { inflammatory response }\end{array}$ & {$[35,64]$} \\
\hline miR-221 & & & & & p27 & DC development/maturation & {$[36,59]$} \\
\hline \multirow[t]{2}{*}{ miR-223 } & & & $\begin{array}{l}\text { IKKa, } \\
\text { NLRP3 }\end{array}$ & $\begin{array}{l}\text { MEF2C } \\
\text { STAT3 }\end{array}$ & & $\begin{array}{l}\text { Monocyte differentiation, granulocyte } \\
\text { proliferation/activation, TLR-induced IL-6/LL-1 } \beta \\
\text { production }\end{array}$ & $\begin{array}{l}{[34,37,69,} \\
74,75]\end{array}$ \\
\hline & & & & & & NLRP3 inflammasome response & \\
\hline miR-23b & & & $\begin{array}{l}\text { TAB2, TAB3, } \\
\text { IKKa }\end{array}$ & & & $\begin{array}{l}\text { IL-17-triggered, TNFa-triggered, and } \\
\text { IL-1 } 1 \text {-triggered inflammatory response }\end{array}$ & [67] \\
\hline miR-29 & IFNy & & & & & IFNy production and NK cell activation & [78] \\
\hline miR-34a & $\begin{array}{l}\text { JAG1 } \\
\text { WNT1 }\end{array}$ & & & & & DC development/maturation & [35] \\
\hline miR-424 & & & & NFI-A & & Monocyte differentiation & [33] \\
\hline miR-9 & & & & NFKB1 & & NF-kB-mediated inflammatory response & [70] \\
\hline
\end{tabular}

to control monocyte differentiation. AML1, the key transcription factor for the process, is directly targeted by miR-17-5p, miR-20a and miR-106a. Expression levels of the three miRNAs are thus downregulated during monocytic differentiation, allowing for the accumulation of AML1, which, in turn, can transcriptionally repress the expression of these miRNAs and promote cell differentiation
[32]. By contrast, miR-424 is upregulated by PU.1, another crucial transcription factor for monocyte/macrophage differentiation, and facilitates the expression of differentiation-specific genes by suppressing the protein level of the inhibitory transcription factor NFI-A [33]. Another study reported an increase in IKK $\alpha$ protein level during monocyte/macrophages differentiation owing to 
substantial decrease in the expression of miR-15a, miR-16, and miR-223, which contributes to $\mathrm{p} 52$ production and prevention of the new macrophage from becoming overactivated [34].

Monocytes can also differentiate into DCs (monocytederived DCs), and miR-21 and miR-34a were shown to be important for this process by cooperatively targeting the mRNAs encoding JAG1 and WNT1 [35]. In addition, a handful of miRNAs are differentially expressed across DC subsets and regulate their fate decision, as miR-221 and miR-222 expression favors conventional DC development, whereas inhibition of the miRNAs skewed precursor cells toward plasmacytoid dendritic cell (pDC) commitment [36]. miRNAs also play important roles in granulocytes and natural killer (NK) cell development $[30,37]$. miR-155 is enriched in hematopoietic stem cells compared with more mature hematopoietic cells; enforced expression of the miRNA in mouse bone marrow cells caused granulocyte/monocyte expansion [38]. However, when miR-146a is depleted, proliferation myeloid cell lineage is observed $[39,40]$.

\section{miR-146a as a crucial negative regulator of innate immune response}

miR-146a and miR-155 are the first miRNAs induced during immune activation and profoundly regulate the innate immune response. In human and murine innate immune cells, transcription of both miRNAs is induced by engagement of several TLRs and inflammatory cytokines or upon viral infection, although the extent and peak induction time may vary [6,41-45]. miR-146a effectively suppresses NF-KB activation and downstream cytokine production (for example, IL-8 induction by IL-1) by various stimuli via a negative feedback loop $[41,46]$. The signaling adaptor proteins TNF receptor-associated family (TRAF)- 6 and IL-1 receptor-associated kinase (IRAK)-1 were identified as direct targets of miR-146a [41]. Because these molecules are also critical signaling components for type I interferon production, miR-146a has also been shown to be able to dampen type I interferon induction by TLR7 and the intracellular sensor retinoic acid-inducible gene-I pathway [43,47]. In this context, the transcription factor interferon regulatory factor-5 and another adaptor IRAK2 were also proved to be miR-146a targets, respectively [43,47]. miR-146a thus inhibits the type I interferon production by simultaneously targeting multiple key components of the induction pathway. In addition, miR-146a suppresses the expression of type I interferon-inducible genes in Akata cell line [44] and in peripheral blood mononuclear cells (PBMCs) via targeting signal transducer and activator of transcription (STAT)-1 [43]. Since these classes of molecules play essential roles in receiving and interpretation of the activation signals, relatively small reductions in their levels could greatly affect the functional response [48]. The overall regulation of the type I interferon induction and action by miR-146a via multiple targets can thus produce great impact, although the inhibitory effect towards each individual target may be modest. Consistent with the in vitro findings, miR-146a-deficient mice display chronic NF-kB activation and develop autoimmune-like disease in aging animals $[39,40]$.

\section{Dual role for miR-155 and opposing action of miR-155/ miR-155* in different settings}

There is extensive evidence supporting miR-155 as a negative regulator of innate immune or inflammatory response. The adaptor protein MyD88 and the kinase IKK $\varepsilon$ were identified as potential targets of miR-155 [49-51]. In monocyte-derived DCs, miR-155 attenuates TLR/IL-1R inflammatory pathway activation by directly targeting the signaling molecule TAB2 [52]. On the contrary, miR-155 promotes inflammatory response of macrophages and also type I interferon signaling via direct inhibition of the canonical negative regulator suppressor of cytokine signaling-1 $[45,53]$. Another study confirmed SH2 domain-containing inositol phosphatase-1 (SHIP1) as a direct target of miR-155; repression of endogenous SHIP1 by miR-155 resulted in increased activation of the kinase AKT during macrophage response to lipopolysaccharide (LPS) [54]. Concordantly, miR-155 transgenic mice produced higher levels of TNF $\alpha$ when exposed to LPS [55]. During acute inflammatory response, induction of miR-155 leads to the suppression of CCAAT/enhancer binding protein beta, which may be responsible for the upregulation of granulocyte colonystimulating factor [56]. The proinflammatory role of miR-155 was also evident in atherosclerotic plaques, where specific expression of miR-155 in macrophages directly inhibits the transcriptional repressor BCL6, leading to the expression of the chemokine CCL2, and thus recruitment of monocytes to the inflammatory site [57]. In addition, several other proteins have been identified as miR-155 targets in DCs, such as PU.1 [58], KPC1 [59], and c-Fos [60], indicating that miR-155 regulates many aspects of DC biology (reviewed in [61]). Indeed, miR-155-deficient DCs fail to effectively activate $\mathrm{T}$ cells $[61,62]$, exemplifying a role for miRNA in regulating the priming of adaptive immune response.

Interestingly, although miR-155 and miR-155* originate from the same precursor, they display opposite effects on the regulation of type I interferon production by $\mathrm{pDCs}$ [6]. In the initial stage of pDC stimulation by TLR7 agonist, the transcriptional activation of the miR-155/ miR-155* gene leads to rapid production of mature miR-155* versus miR-155. This results in the degradation of its target IRAKM, a negative regulator that blocks TLR7 pathway activation in resting pDCs, thereby 
facilitating type I interferon production. Simultaneously, both TLR7 stimulation and the autocrine/paracrine signaling of IFN $\alpha / \beta$ lead to gradual accumulation and activation of KSRP, which promote miR-155 maturation at the post-transcriptional level. In the later stage of activation, therefore, expression of miR-155 dominates whereas miR-155* levels decrease sharply. Targeting TAB2 by miR-155 in pDCs confers negative regulation of the activation signaling, thus maintaining type I interferon production and pDC activation at a proper level [6].

\section{Other miRNAs targeting innate immune signaling molecules}

miRNA-mediated regulation of other molecules in the TLR signaling cascades can also effectively control or fine-tune the innate immune response. miR-145 was shown to target the bridging adaptor MAL [63]. miR-21 inhibits the expression of proinflammatory regulator PDCD4 after TLR4 engagement [64]. A couple of signaling proteins in the TLR4 pathway were predicted as potential targets for miR-200 family members (miR-200a/ $\mathrm{b} / \mathrm{c}$ ); however, a reporter gene screening showed that only the MyD88 3' UTR was targeted by miR-200b/c, which was confirmed by mutational analysis [65]. Consequently, overexpression of miR-200b/c inhibited NF- $\mathrm{kB}$ reporter activity and TLR4-induced inflammatory cytokine expression [65]. CaMKII $\alpha$ is a major downstream effector of calcium and plays an important role in promoting TLR signaling-induced DC maturation and function. Upregulation of members of the miR-148 family (miR-148a/b and miR-152) in DCs by several TLR agonists leads to targeted inhibition of CaMKII $\alpha$, which results in suppression of cytokine production, reduced MHC II surface expression and DC-initiated antigenspecific T-cell proliferation [66], demonstrating a role for miRNAs other than miR-155 in regulating antigenpresenting capacity of DCs.

In a recent study, the concomitant regulation of TAB2, TAB3, and IKKa by miR-23b was reported, which is responsible for the critical suppression of NF- $\mathrm{kB}$ activation and inflammatory cytokine production induced by IL-17, TNF $\alpha$, or IL-1 $\beta$ [67]. Importantly, miR-23b is downregulated by IL-17 stimulation [67]. Despite the recent research focus on IL-17 as a T-cell-secreted cytokine, many innate immune cell populations release a high amount of $\mathrm{IL}-17$ at the early stage of an immune response, which is central to the initiation of IL-17dependent immune responses [68]. Downregulation of miR-23b by IL- 17 would therefore play a profound role in regulating the innate immune activation.

miRNA-mediated regulation is also dictated to targeting transcription factors that are instrumental in generating an innate immune response, as exemplified by
miR-146a (targeting interferon regulatory factor- 5 and STAT1) discussed above. In macrophages, downregulation of miR-223 by TLR3 and TLR4 agonists results in derepression of its target STAT3 and, thus, in enhanced production of IL- 6 and IL-1 $\beta$ but not TNF $\alpha$ [69]. miR-9 is induced by LPS in both monocytes and neutrophils and directly targets NFKB1 mRNA, representing another important feedback control of NF-KB-dependent responses [70]. In the IL-10-driven anti-inflammatory response, miR-187 was shown to be induced to downregulate the production of several inflammatory cytokines by activated monocytes. One relevant target identified for miR-187 is $\mathrm{I} \mathrm{B} \zeta$, which is a key transcriptional regulator of IL-6 and IL-12p40 [71].

miRNAs have also been shown to directly target mRNAs encoding individual TLRs [72]. TLR4 expression is thus inhibited by let-7e in macrophages [53], whereas TLR2 is targeted by miR-19a/b [73]. The miRNAmediated regulation of TLR signaling pathways is summarized in Figure 1.

In the context of NLR-mediated inflammatory response, two very recent studies independently reported the direct regulation of NLR family PYD-containing protein 3 (NLRP3) and, consequently, inhibition of IL-1 $\beta$ production from the NLRP3 inflammasome by miR-223 $[74,75]$.

\section{Direct targeting of cytokine mRNAs}

In addition to the preferential regulation via signaling molecules, several cytokine mRNAs also fall into direct control by miRNA [72]. In addition to indirect suppression of IL- 6 and IL-12p40 by miR-187 discussed above, this miRNA also directly inhibits TNF $\alpha$ mRNA expression and translation in monocytes [71]. The 3' UTR of TNF $\alpha$ mRNA also harbors a binding site for miR-125b, and downregulation of the miRNA by LPS stimulation may help stabilize TNF $\alpha$ expression [55]. IL-6 mRNA is directly targeted by miR-142-3p; silencing of miR-142-3p leads to enhanced IL-6 production both in immature DCs and following LPS activation [76].

The results of another study revealed direct inhibition of IL-10 expression by miR-106a [77]. Ma and colleagues found that NK cells activated in vivo (that is, from mice infected with an intracellular pathogen) or in vitro by the innate immune ligand poly(I:C) downregulated their expression of miR-29 while producing a large amount of IFNY [78]. They further showed a direct interaction between miR-29 and IFNY mRNA: in addition to evidence that mutation of the predicted miR-29 binding sites abolished its inhibitory effect on IFNY 3'-UTR reporter gene activity, the authors detected elevated association of IFN $\gamma$ mRNA with the Ago2-containing complex in cells transfected with synthetic miR-29a mimic using an immunoprecipitation approach with an 


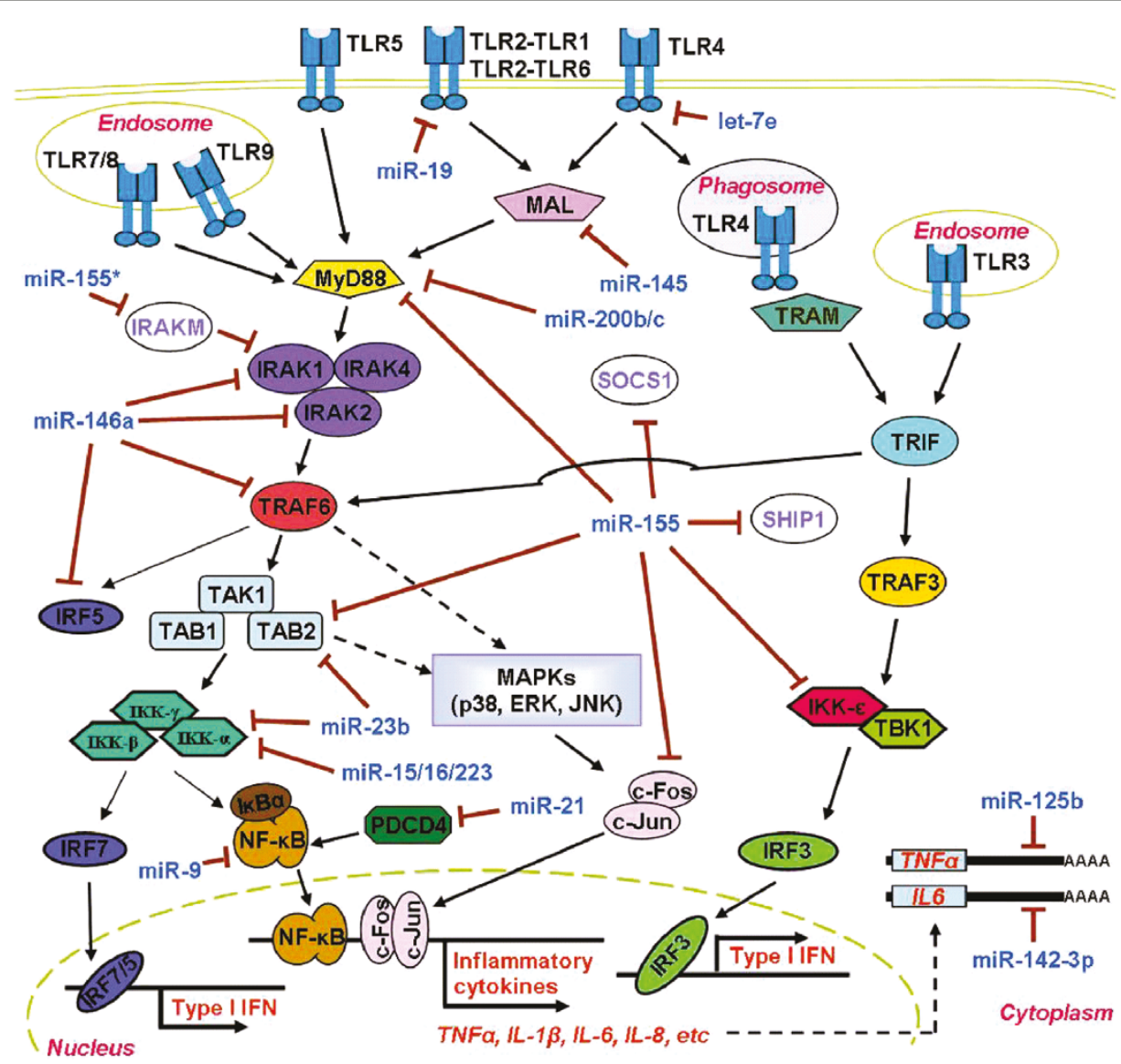

Figure 1. Schematic presentation of select miRNAs that regulate toll-like receptor signaling pathways. During innate immune response, toll-like receptors (TLRs) are activated by various pathogens and initiate signaling transduction to induce the production of type I interferons (IFNs) and other inflammatory cytokines. miRNAs exert pronounced control of the pathway activation at multiple levels to ensure the generation of proper immune response. The miRNAs preferentially target the common signaling components and transcription factors, but also directly act on receptors and cytokine mRNAs. In most cases, decreases in the concentrations of miRNA target proteins achieve effective negative regulation and therefore avoid detrimental immune activation. However, if the target protein itself is a negative regulator (IL-1 receptor-associated kinase (IRAK)-M, suppressor of cytokine signaling-1 (SOCS1), SH2 domain-containing inositol phosphatase-1 (SHIP1)), miRNA-mediated regulation will facilitate TLR signaling and the production of inflammatory cytokines. ERK, extracellular signal-regulated kinase; IFR, interferon regulatory factor; IKK, I-kappa-B kinase; MAL, MyD88 adapter-like; MAPK, mitogen-activated protein kinase; TAB, TAK1-binding protein; TAK, transforming growth factor-beta activated kinase; TBK, TANK-binding kinase; TRAM, TRIF-related adapter molecule; TRAF, TNF receptor-associated factor; TRIF, TIR domain containing adaptor inducing IFN $\beta$.

antibody against Ago2 [78]. The importance of miR-29 in regulating the immune response to intracellular bacterial infection (via targeting IFNY) was further demonstrated in vivo by competitive inhibition of miR-29 by transgenic expression of a sponge target [78].

\section{miRNAs take action in host-virus interaction}

Compelling evidence demonstrates that miRNAs are directly incorporated into host-virus interactions, providing another layer to the innate immune response $[31,79]$. For instance, host cell miR-32 can recognize and bind to five viral mRNAs, contributing to the repression of the replication of the retrovirus primate foamy virus type 1 [80]. In addition to the induction of a plethora of well-known antiviral proteins, IFN $\beta$ is also found to stimulate the expression of several miRNAs that target the genome of hepatitis C virus [81]. Simultaneously, IFN $\beta$ suppresses the expression of miR-122, a host miRNA that is utilized by hepatitis $C$ virus to promote its replication.

In the context of viral exploitation of miRNAs for their own advantage, some virus-encoded miRNAs target host mRNAs to evade immune surveillance or dampen the immune response. For instance, hcmv-miR-UL112 represses the expression of histocompatibility complex class I-related chain B and consequently impairs NK cell activation and killing infected cells [82]. The EpsteinBarr virus-encoded miRNA, miR-BART15, represses the 
expression of NLRP3, and thus IL-1 $\beta$ production [74]. Furthermore, this viral miRNA can be secreted and transferred via exosomes to inhibit the NLRP3 inflammasome capacity in noninfected cells [74]. Such direct interactions between virus-encoded and host-encoded nucleic acids provide another dimension to innate immunity [79]. Since viral infection has also been implicated in rheumatic disease onset or flare and Epstein-Barr virus is considered a major environmental risk factor for systemic lupus erythematosus (SLE) [83], the involvement of miRNA in host-virus interaction may also have some relevance to rheumatic disease pathogenesis.

\section{Dysregulation of miRNA and innate immune response in rheumatic diseases}

It becomes evident now that miRNAs mediate dynamic regulation at multiple levels that essentially controls innate immune cell development and activation, inflammatory cytokine production and signaling, and antigen presentation. Dysregulated miRNA expression or function could severely affect the duration and extent of innate immune response and be detrimental. Indeed, emerging data underscore the role of excessive or protracted innate immune signaling in the pathogeneses of autoimmune and autoinflammatory rheumatic diseases [83-85], which has been linked to dysregulation of critical miRNAs.

\section{Systemic lupus erythematosus}

SLE is a prototypical autoimmune disease with a hallmark of chronic immune activation and multiple immunologic alterations. To identify dysregulated miRNAs in SLE, a profiling analysis of 156 miRNAs was undertaken to compare their expression levels in the peripheral blood leukocytes from patients with SLE and healthy subjects. This led to the identification of underexpression of miR146a in SLE [43], which appeared to be a primary defect caused by lupus-associated germline variant in miR-146a promoter [86], rather than a consequence of disease onset or medication [43]. In the same study, a reverse correlation of miR-146a levels with disease activity and with interferon score was identified, which reflects the magnitude of type I interferon pathway activation in patients with SLE. This indicates that decreased expression of miR-146a would result in inadequate regulation of the multiple target proteins and consequently overproduction of type I interferons and unabated downstream activation [43]. Importantly, enforced expression of miR146a in PBMCs from patients with active SLE attenuated the mRNA levels of several interferon-inducible genes [43], strongly supporting the contribution of miR-146a dysregulation to such molecular phenotype of SLE.

Other miRNAs with a known role in innate immune response and dysregulated in SLE include miR-21, miR142-3p, miR-148a/b, and miR-155, all of which are upregulated in PBMCs in patients with SLE $[87,88]$. However, the contribution of these miRNAs in SLE pathogenesis via dysregulated innate immune response still needs to be determined. Stagakis and colleagues reported that the expression of the miR-21 target gene PDCD4 [64] is correspondingly decreased in active SLE, but suggested that their interaction affects aberrant T-cell responses in SLE in humans [88].

\section{Rheumatoid arthritis}

Rheumatoid arthritis (RA) is a systemic autoimmune disease that causes irreversible joint damage. Investigation of the expression and contribution of miRNAs in RA is very active and has revealed the dysregulation of several miRNAs in various cells/tissues, including PBMCs, the synovial tissue, isolated fibroblast-like synoviocytes (FLS), and cell-free synovial fluid (reviewed in [89]). The joint resident cells, FLS are unique for RA in that they, like innate immune cells, express several TLRs, are implicated in inflammatory response, and play critical roles in osteoarticular destruction [73]. Stimulation of RA FLS with LPS or bacterial lipoprotein strongly induced TLR2 expression while suppressing the levels of miR-19a/b, which directly targets TLR2 mRNA [73]. Supporting a role for miR-19a/b in regulating $\mathrm{RA}$ inflammation, transfection of the miRNA mimic significantly downregulated the release of IL-6 and matrix metalloproteinase- 3 by TLR2-activated RA FLS [73]. Secretion of IL-6 and matrix metalloproteinase-1 also appears to be indirectly regulated by miR-203, which is highly expressed in RA FLS [90].

Compared with osteoarthritis, miR-155 is significantly upregulated in RA FLS, whose expression can be further induced by TNF $\alpha$, IL-1 $\beta$, and by ligands of TLR 2 through TLR4. This indicates that the inflamed milieu may be responsible for the altered expression of miR-155 in these cells [91]. Moreover, miR-155 is also highly expressed in synovial fluid-derived monocytes/macrophages compared with the peripheral blood counterparts from patients with RA [91,92], whereas both mRNA and protein levels of the miR-155 target SHIP1 are decreased [92]. Incubation of peripheral blood CD14 $4^{+}$cells with RA synovial fluid stimulated the expression of miR-155 and release of TNF $\alpha$; the cytokine production was abrogated by transfection of miR-155 inhibitor [92]. Direct evaluation of the regulation in RA synovial CD14+ ${ }^{+}$cells revealed inhibition of miR-155 augmented SHIP1 expression and downregulated TNF $\alpha$ production when these cells were reactivated by LPS [92]. Moreover, the authors of this study and another group independently showed that miR-155 knockout mice did not develop collageninduced arthritis (CIA) where significantly lower production of many proinflammatory cytokines was observed $[92,93]$. One should note here that, in addition to the 
essential regulation of monocyte/macrophage activation and of DCs in priming the adaptive immune response, miR-155 is also directly required for proper function of $\mathrm{T}$ cells and $\mathrm{B}$ cells $[30,62]$. Clearly, the protective role of miR-155 deficiency in the CIA model resulted from the combinatory effect on both innate and adaptive immune responses [92,93].

miR-223 is also significantly overexpressed in RA FLS and synovial fluid $[89,94,95]$. Intriguingly, when a lentiviral vector expressing the miR-223 target sequence was intraperitoneally administrated to mice with CIA to abrogate miR-223 function, the severity of experimental arthritis was markedly reduced. This suggested a potential therapeutic strategy [95], although the extent and contribution of miR-223 silencing in distinct cell types needs detailed examination.

To identify novel miRNAs associated with RA pathology, Pandis and colleagues started with a different approach. They first applied deep sequencing to examine the miRNA expression profile of FLS isolated from the human TNF transgenic mouse model (TghuTNF) [96]. A number of dysregulated miRNAs were identified, including miR-155 and miR-223 that are known to be upregulated in FLS of RA patients. The expression levels of select miRNAs were further quantified in patient biopsies, and the upregulation of miR-221, miR-222 and miR-323-3p was also consistently found to be associated in human RA [96].

Interestingly, miR-23b was found to be underexpressed in RA synovial tissue and in the joints of mice with CIA, in the kidneys of patients with SLE and the MRL/lpr mouse model, and in experimental autoimmune encephalomyelitis mice, which may be a result of IL-17mediated transcriptional inhibition [67]. The results of this study provide in vivo evidence that miR-23b could suppress autoimmune disease pathogenesis, although the expression of this miRNA in resident cells in inflammatory lesions appears to be vital in this regard [67].

\section{Upregulated expression of miR-146a in rheumatoid arthritis, Sjögren's syndrome, and myositis}

In contrast to the decreased expression of miR-146a in SLE, patients with RA display higher expression of miR146a in both FLS [91,97] and PBMCs [98], with a hint that the alteration primarily occurs in monocytes/ macrophages [98]. Although miR-146a does target IRAK1 and TRAF6 mRNA for degradation [99], their expression in PBMCs in patients with RA is similar to that in healthy subjects [98]. The results of a recent study revealed overexpression of miR-146a in PBMCs of patients with Sjögren's syndrome, which is also observed in PBMCs and the salivary glands in an animal model of the disease [99]. In another study, increased expression of both miR-146a and miR-146b in patients with Sjögren's syndrome was observed [100]. In PBMCs from patients with Sjögren's syndrome, the mRNA level of IRAK1 is decreased while that of TRAF6 is increased when examined in a small number of subjects $(n=9$ for patients and $n=10$ for healthy subjects, respectively [100]). Altered miRNA levels were also identified in patients with myositis; the expression of miR-146a was found to be elevated, probably due to leukocyte infiltration [101]. Although the 31 patients with myositis examined displayed a general signature of type I interferon pathway activation, six out of eight patients with dermatomyositis examined had reverse correlation between miR-146a levels and type I interferon gene signature [101]. Further studies are warranted to explore the reason for increased expression of miR-146a and its contribution to such rheumatic diseases.

\section{Scleroderma}

Plenty of studies have also been performed by Ihn's group to identify scleroderma-associated miRNAs - several miRNAs including miR-29a and miR-196a were found to be dysregulated, either in skin biopsy or fibroblast samples, or in the serum from scleroderma patients $[102,103]$. Given that recent studies have provided new insights into the role of the innate immune system in scleroderma [104], the potential contribution of miRNAmediated dysregulation of innate immune response to scleroderma pathology is yet to be explored.

\section{Extracellular miRNAs: a missing link between innate immune response and rheumatic disease?}

The presence of miRNAs in body fluids attracts a lot of attention. There are examples of the extracellular miRNAs entering into and maintaining their regulatory function in recipient cells [26,27], but further evidence is awaited. Another major focus of current studies is the identification of certain circulating miRNAs as disease biomarkers.

Nevertheless, the results of two recent studies suggested an unconventional role for miRNAs and an intriguing link between miRNAs in body fluids and innate immune signaling in disease settings. Lehmann and colleagues identified an increase in let- $7 \mathrm{~b}$ levels in the cerebrospinal fluid from individuals with Alzheimer's disease and provided in vivo evidence that extracellular let-7 acts as an RNA ligand to activate neuronally expressed TLR7 and induce neurodegeneration [105]. The results of another study showed that miR-21 and miR-29a in the cancer cell-derived exosomes are able to bind murine TLR7 and human TLR8 and to induce a prometastatic inflammatory response [106].

Although the exact structural features in the sequence of such miRNAs that confer their capacity to activate TLR7/8 require more studies, they all appear to harbor a GU-rich motif, which is known to be present in 
TLR7/8-stimulating virus-derived RNAs [105,106]. Supporting this idea, miR-599, miR-147, and miR-5745 p, which also contain GU-rich motifs, similarly induce TLR7/8-dependent cytokine production [105,106]. Given the more direct relevance of such an innate immune pathway to rheumatic diseases, and given the dysregulated miRNA levels in the body fluids of patients with such disorders systemically (in serum) and/or locally (such as in RA synovial fluid) [89], it would be interesting to examine such a link in a specific rheumatic disease.

\section{Conclusion}

miRNA appears to preferentially target signaling proteins and transcription factors (Figure 1), molecules that are instrumental for dictating the extracellular stimuli and driving the development and activation of innate immune cells. Some miRNAs simultaneously regulate the expression of multiple proteins (for example, targeting of IRAK1, TRAF6, interferon regulatory factor-5, and STAT1 by miR-146a), thus effectively controlling the activation of innate immune signaling cascade. Some other miRNAs bind to the same site (for example, targeting of CaMKII $\alpha$ by miR-148 family members) or separate ones (for example, targeting of IKKa by miR-15a, miR-16, and miR-223) within a single mRNA and coordinately control the expression of a common target. In addition, miRNAs also directly target mRNAs encoding innate immune receptors, such as TLR4 and TLR2, or inflammatory cytokines, such as TNF $\alpha$, IL- 6 and IFN $\gamma$. miRNAs may also exert their regulation through inhibition of some relevant targets that are previously not linked to the innate immune response or that display an important function in other cellular pathways, and thus one might expect a careful analysis of putative targets to lead to the identification of novel genes involved in some aspects of innate immunity or to provide a missing link between innate immune and other cellular pathways [107].

In many cases, the expression of specific miRNAs is upregulated via transcriptional activation (for instance, NF- $k B-d e p e n d e n t$ induction) to decrease the concentration of their target proteins. In other scenarios, the miRNA expression is downregulated to allow for the accumulation of its target (for example, decreased miR-29 expression with increased IFNY production during NK cell activation). The post-transcriptional regulation adds another layer of control of miRNA expression during an innate immune response, enabling selective modulation of levels of certain mature miRNAs, and ensuring miRNA-mediated regulation to be exerted more precisely, as in the case of KSRP-promoted maturation of miR-155 during pDC activation. Molecules mediating signaling activation are not only targeted by miRNAs, but several negative regulators are also under miRNAmediated control (for example, targeting of suppressor of cytokine signaling-1 and SHIP1 by miR-155). miRNAs thus regulate innate immune response at multiple levels. Depending on the nature of the target proteins, miRNAs can either suppress or facilitate distinct aspects of immune activation, and ultimately maintain the balance of innate immune response. Altered expression of critical miRNAs, such as miR-146a and miR-155, thus profoundly contributes to the pathogeneses of rheumatic diseases, where dysregulation of their target proteins leads to unabated inflammatory cytokine production and signaling, and aberrant priming of adaptive immune response. With the application of new technologies, such as deep sequencing, one would expect that more miRNAs or functional isoforms will be identified to have a role in regulating innate immune response and dysregulation in rheumatic diseases. This would particularly provide insight into autoinflammatory disorders, where activation of the innate immune system alone is sufficient to induce the disease [83].

On the contrary, although the importance of miRNAmediated regulation of innate immune response should be highly appreciated, one should notice that a considerable fraction of miRNAs discussed here are also critical regulators of adaptive immune response (for example, miR-155, which also regulates T-cell and B-cell function, as evidenced by knockout mice). This is particularly important in disease settings, because dysregulation of adaptive immune response is considered indispensable in the pathogenesis of autoimmune rheumatic diseases [83]; in many studies, altered expression of miRNAs in PBMCs or diseased tissue with leukocyte infiltration, instead of purified innate immune cells, was observed. Moreover, some miRNAs may even simultaneously regulate processes beyond immune system but essentially related to disease pathogenesis. For instance, miR-155, miR-223 and miR-21 promote osteoclastogenesis [93, 108-110] while miR-146a inhibits it [111]. The effect of these miRNAs on local bone destruction in RA has been demonstrated in animal models [93,111]. miRNA knockout mice would thus provide unambiguous evidence for the physiological and pathological roles of specific miRNAs in the innate immune system and in other processes.

One should still pay attention to the strategy applied, however, as both the target miRNA and its star form partner will be depleted. For example, it would be interesting to hypothesize whether there is any phenotype reported for miR-155 deficiency actually attributable to loss of miR-155*. This query would require a thorough investigation of the distinct contribution of critical targets of each miRNA, as occurred for demonstration of targeting activation-induced cytidine deaminase by miR-155 in vivo $[112,113]$. With a better understanding of the contribution of dysregulation of miRNAs to the 
aberrant immune activation and, consequently, pathogeneses of rheumatic diseases, we would further explore the promise that miRNAs hold for developing new therapeutic targets.

This article is part of the series on Epigenetics and rheumatic diseases, edited by Nan Shen. Other articles in this series can be found at http://arthritis-research.com/series/epigenetics

\section{Abbreviations}

CIA, collagen-induced arthritis; DC, dendritic cell; FLS, fibroblast-like synoviocytes; IFN, interferon; IL, interleukin; IRAK, LL-1 receptor-associated kinase; KSRP, KH-type splicing regulatory protein; LPS, lipopolysaccharide; miRNA, microRNA; miRNA*, star-form miRNA; NF, nuclear factor; NK, natural killer; NLR, nucleotide-binding oligomerization domain-like receptor; NLRP3, NLR family PYD-containing protein 3; PBMC, peripheral blood mononuclear cell; pDC, plasmacytoid dendritic cell; RA, rheumatoid arthritis; RISC, RNA-induced silencing complex; SHIP1, SH2 domain-containing inositol phosphatase-1; SLE, systemic lupus erythematosus; STAT, signal transducer and activator of transcription; TLR, toll-like receptor; TNF, tumor necrosis factor; TRAF, TNF receptor-associated factor; UTR, untranslated region.

\section{Competing interests}

The authors declare that they have no competing interests.

\section{Acknowledgments}

This work was partially supported by the National Natural Science Foundation of China (No.30971632, No.81230072,No.81025016) and the Program of the Shanghai Commission of Science and Technology (No.12JC1406000, No.10JC1409300)

\section{Author details}

'Joint Molecular Rheumatology Laboratory of Institute of Health Sciences and Shanghai Renji Hospital, Shanghai JiaoTong University School of Medicine and Shanghai Institutes for Biological Sciences, Chinese Academy of Sciences, 145 Shan Dong Middle Road, Shanghai 200001, China. ${ }^{2}$ Medlmmune, One Medlmmune Way, Gaithersburg, MD 20878, USA. ${ }^{3}$ School of Pre-Clinical Medicine, Downing College, University of Cambridge, Cambridge CB2 1DQ UK.

Published: 9 April 2013

\section{References}

1. Bartel DP: MicroRNAs: genomics, biogenesis, mechanism, and function Cell 2004, 116:281-297.

2. Krol J, Loedige I, Filipowicz W: The widespread regulation of microRNA biogenesis, function and decay. Nat Rev Genet 2010, 11:597-610

3. Paroo Z, YeX, Chen S, Liu Q: Phosphorylation of the human microRNAgenerating complex mediates MAPK/Erk signaling. Cell 2009, 139:112-122.

4. Trabucchi M, Briata P, Garcia-Mayoral M, Haase AD, Filipowicz W, Ramos A, Gherzi R, Rosenfeld MG: The RNA-binding protein KSRP promotes the biogenesis of a subset of microRNAs. Nature 2009, 459:1010-1014

5. Ruggiero T, Trabucchi M, De Santa F, Zupo S, Harfe BD, McManus MT, Rosenfeld MG, Briata P, Gherzi R: LPS induces KH-type splicing regulatory protein-dependent processing of microRNA-155 precursors in macrophages. FASEB J 2009, 23:2898-2908.

6. Zhou H, Huang $X$, Cui H, Luo X, Tang $Y$, Chen S, Wu L, Shen N: miR-155 and its star-form partner miR-155* cooperatively regulate type I interferon production by human plasmacytoid dendritic cells. Blood 2010, 116:5885-5894.

7. Okamura K, Phillips MD, Tyler DM, Duan H, Chou YT, Lai EC: The regulatory activity of microRNA* species has substantial influence on microRNA and 3'UTR evolution. Nat Struct Mol Biol 2008, 15:354-363.

8. Grimson A, Farh KK, Johnston WK, Garrett-Engele P, Lim LP, Bartel DP: MicroRNA targeting specificity in mammals: determinants beyond seed pairing. Mol Cell 2007, 27:91-105.

9. Zeng Y, Sankala H, Zhang X, Graves PR: Phosphorylation of Argonaute 2 at serine-387 facilitates its localization to processing bodies. Biochem $J 2008$ 413:429-436.
10. Kim HH, Kuwano Y, Srikantan S, Lee EK, Martindale JL, Gorospe M: HuR recruits let-7/RISC to repress C-Myc expression. Genes Dev 2009, 23:1743-1748.

11. Bhattacharyya SN, Habermacher R, Martine U, Closs El, Filipowicz W: Relief of microRNA-mediated translational repression in human cells subjected to stress. Cell 2006, 125:1111-1124

12. Landgraf P, Rusu M, Sheridan R, Sewer A, lovino N, Aravin A, Pfeffer S, Rice A, Kamphorst AO, Landthaler M, Lin C, Socci ND, Hermida L, Fulci V, Chiaretti S, Foà R, Schliwka J, Fuchs U, Novosel A, Müller RU, Schermer B, Bissels U, Inman J, Phan Q, Chien M, Weir DB, Choksi R, De Vita G, Frezzetti D, Trompeter HI, et al: A mammalian microRNA expression atlas based on small RNA library sequencing. Cell 2007, 129:1401-1414.

13. Nishikura K: Functions and regulation of RNA editing by ADAR deaminases. Annu Rev Biochem 2010, 79:321-349.

14. Hafner $M$, Landthaler $M$, Burger $L$, Khorshid M, Hausser J, Berninger $P$, Rothballer A, Ascano M, Jr, Jungkamp AC, Munschauer M, Ulrich A, Wardle GS, Dewell S, Zavolan M, Tuschl T: Transcriptome-wide identification of RNAbinding protein and microRNA target sites by PAR-CLIP. Cell 2010, 141:129-141.

15. Tay Y, Zhang J, Thomson AM, Lim B, Rigoutsos I: MicroRNAs to Nanog, Oct4 and Sox 2 coding regions modulate embryonic stem cell differentiation. Nature 2008, 455:1124-1128.

16. Pan W, Zhu S, Yuan M, Cui H, Wang L, Luo X, Li J, Zhou H, Tang Y, Shen N: MicroRNA-21 and microRNA-148a contribute to DNA hypomethylation in lupus $\mathrm{CD}^{+} \mathrm{T}$ cells by directly and indirectly targeting DNA methyltransferase 1. J Immunol 2010, 184:6773-6781.

17. Shin C, Nam JW, Farh KK, Chiang HR, Shkumatava A, Bartel DP: Expanding the microRNA targeting code: functional sites with centered pairing. Mol Cell 2010, 38:789-802.

18. Orom UA, Nielsen FC, Lund AH: MicroRNA-10a binds the $5^{\prime}$ UTR of ribosomal protein mRNAs and enhances their translation. Mol Cell 2008, 30:460-471.

19. Vasudevan S, Tong Y, Steitz JA: Switching from repression to activation: microRNAs can up-regulate translation. Science 2007, 318:1931-1934.

20. Eiring AM, Harb JG, Neviani P, Garton C, Oaks JJ, Spizzo R, Liu S, Schwind S, Santhanam R, Hickey CJ, Becker H, Chandler JC, Andino R, Cortes J, Hokland P, Huettner CS, Bhatia R, Roy DC, Liebhaber SA, Caligiuri MA, Marcucci G, Garzon R, Croce CM, Calin GA, Perrotti D.: miR-328 functions as an RNA decoy to modulate hnRNP E2 regulation of mRNA translation in leukemic blasts. Cell 2010, 140:652-665.

21. Poliseno L, Salmena L, Zhang J, Carver B, Haveman WJ, Pandolfi PP: A codingindependent function of gene and pseudogene mRNAs regulates tumour biology. Nature 2010, 465:1033-1038.

22. Cesana M, Cacchiarelli D, Legnini I, Santini T, Sthandier O, Chinappi M, Tramontano A, Bozzoni l: A long noncoding RNA controls muscle differentiation by functioning as a competing endogenous RNA. Cell 2011, 147:358-369.

23. Karreth FA, Tay Y, Perna D, Ala U, Tan SM, Rust AG, DeNicola G, Webster KA, Weiss D, Perez-Mancera PA, Krauthammer M, Halaban R, Provero P, Adams D」, Tuveson DA, Pandolf PP: In vivo identification of tumor-suppressive PTEN ceRNAs in an oncogenic BRAF-induced mouse model of melanoma. Cell 2011, 147:382-395

24. Tay Y, Kats L, Salmena L, Weiss D, Tan SM, Ala U, Karreth F, Poliseno L, Provero P, Di Cunto F, Lieberman J, Rigoutsos I, Pandolfi PP: Coding-independent regulation of the tumor suppressor PTEN by competing endogenous mRNAs. Cell 2011, 147:344-357.

25. Pasquinelli AE: MicroRNAs and their targets: recognition, regulation and an emerging reciprocal relationship. Nat Rev Genet 2012, 13:271-282.

26. Zhang Y, Liu D, Chen X, Li J, Li L, Bian Z, Sun F, Lu J, Yin Y, Cai X, Sun Q, Wang K, Ba Y, Wang Q, Wang D, Yang J, Liu P, Xu T, Yan Q, Zhang J, Zen K, Zhang CY: Secreted monocytic miR-150 enhances targeted endothelial cell migration. Mol Cell 2010, 39:133-144

27. Cortez MA, Bueso-Ramos C, Ferdin J, Lopez-Berestein G, Sood AK, Calin GA: MicroRNAs in body fluids - the mix of hormones and biomarkers. Nat Rev Clin Oncol 2011, 8:467-477.

28. Chen CZ, Li L, Lodish HF, Bartel DP: MicroRNAs modulate hematopoietic lineage differentiation. Science 2004, 303:83-86.

29. Baltimore D, Boldin MP, O'Connell RM, Rao DS, Taganov KD: MicroRNAs: new regulators of immune cell development and function. Nat Immunol 2008, 9:839-845

30. O'Connell RM, Rao DS, Chaudhuri AA, Baltimore D: Physiological and 
pathological roles for microRNAs in the immune system. Nat Rev Immunol 2010, 10:111-122.

31. Xiao C, Rajewsky K: MicroRNA control in the immune system: basic principles. Cell 2009, 136:26-36.

32. Fontana L, Pelosi E, Greco P, Racanicchi S, Testa U, Liuzzi F, Croce CM, Brunetti E, Grignani F, Peschle C: MicroRNAs 17-5p-20a-106a control monocytopoiesis through AML1 targeting and M-CSF receptor upregulation. Nat Cell Biol 2007, 9:775-787.

33. Rosa A, Ballarino M, Sorrentino A, Sthandier O, De Angelis FG, Marchioni M, Masella B, Guarini A, Fatica A, Peschle C, Bozzoni I: The interplay between the master transcription factor PU.1 and miR-424 regulates human monocyte/ macrophage differentiation. Proc Natl Acad Sci U S A 2007, 104:19849-19854.

34. LiT, Morgan MJ, Choksi S, Zhang Y, Kim YS, Liu ZG: MicroRNAs modulate the noncanonical transcription factor NF-KB pathway by regulating expression of the kinase IKKa during macrophage differentiation. Nat Immunol 2010, 11:799-805.

35. Hashimi ST, Fulcher JA, Chang MH, Gov L, Wang S, Lee B: MicroRNA profiling identifies miR-34a and miR-21 and their target genes JAG1 and WNT1 in the coordinate regulation of dendritic cell differentiation. Blood 2009 114:404-414.

36. Kuipers H, Schnorfeil FM, Brocker T: Differentially expressed microRNAs regulate plasmacytoid vs. conventional dendritic cell development. $\mathrm{Mol}$ Immunol 2010, 48:333-340.

37. Johnnidis JB, Harris MH, Wheeler RT, Stehling-Sun S, Lam MH, Kirak O, Brummelkamp TR, Fleming MD, Camargo FD: Regulation of progenitor cell proliferation and granulocyte function by microRNA-223. Nature 2008, 451:1125-1129.

38. O'Connell RM, Rao DS, Chaudhuri AA, Boldin MP, Taganov KD, Nicoll J, Paquette RL, Baltimore D: Sustained expression of microRNA-155 in hematopoietic stem cells causes a myeloproliferative disorder. J Exp Med 2008, 205:585-594

39. Zhao JL, Rao DS, Boldin MP, Taganov KD, O'Connell RM, Baltimore D: NF-kappaB dysregulation in microRNA-146a-deficient mice drives the development of myeloid malignancies. Proc Natl Acad Sci U S A 2011, 108:9184-9189.

40. Boldin MP, Taganov KD, Rao DS, Yang L, Zhao JL, Kalwani M, Garcia-Flores Y, Luong M, Devrekanli A, Xu J, Sun G, Tay J, Linsley PS, Baltimore D: miR-146a is a significant brake on autoimmunity, myeloproliferation, and cancer in mice. J Exp Med 2011, 208:1189-1201.

41. Taganov KD, Boldin MP, Chang KJ, Baltimore D: NF-KB-dependent induction of microRNA miR-146, an inhibitor targeted to signaling proteins of innate immune responses. Proc Natl Acad Sci U S A 2006, 103:12481-12486.

42. O'Connell RM, Taganov KD, Boldin MP, Cheng G, Baltimore D: MicroRNA-155 is induced during the macrophage inflammatory response. Proc Natl Acad SciUS A 2007, 104:1604-1609.

43. Tang Y, Luo X, Cui H, Ni X, Yuan M, Guo Y, Huang X, Zhou H, de Vries N, Tak PP, Chen S, Shen N: MicroRNA-146A contributes to abnormal activation of the type I interferon pathway in human lupus by targeting the key signaling proteins. Arthritis Rheum 2009, 60:1065-1075.

44. Cameron JE, Yin Q, Fewell C, Lacey M, McBride J, Wang X, Lin Z, Schaefer BC, Flemington EK: Epstein-Barr virus latent membrane protein 1 induces cellular microRNA miR-146a, a modulator of lymphocyte signaling pathways. J Virol 2008, 82:1946-1958.

45. Wang P, Hou J, Lin L, Wang C, Liu X, Li D, Ma F, Wang Z, Cao X: Inducible microRNA-155 feedback promotes type I IFN signaling in antiviral innate immunity by targeting suppressor of cytokine signaling 1. J /mmuno/ 2010, 185:6226-6233.

46. Perry MM, Moschos SA, Williams AE, Shepherd NJ, Larner-Svensson HM, Lindsay MA: Rapid changes in microRNA-146a expression negatively regulate the IL-1 $\beta$-induced inflammatory response in human lung alveolar epithelial cells. J Immuno/ 2008, 180:5689-5698.

47. Hou J, Wang $P$, Lin L, Liu X, Ma F, An H, Wang Z, Cao X: MicroRNA-146a feedback inhibits RIG-I-dependent Type I IFN production in macrophages by targeting TRAF6, IRAK1, and IRAK2. J Immuno/ 2009, 183:2150-2158.

48. O'Connell RM, Rao DS, Baltimore D: microRNA regulation of inflammatory responses. Annu Rev Immunol 2012, 30:295-312.

49. Gottwein E, Mukherjee N, Sachse C, Frenzel C, Majoros WH, Chi JT, Braich R, Manoharan M, Soutschek J, Ohler U, Cullen BR: A viral microRNA functions as an orthologue of cellular miR-155. Nature 2007, 450:1096-1099.

50. Xiao B, Liu Z, Li BS, Tang B, Li W, Guo G, Shi Y, Wang F, Wu Y, Tong WD, Guo H, Mao XH, Zou QM: Induction of microRNA-155 during Helicobacter pylori infection and its negative regulatory role in the inflammatory response. $J$ Infect Dis 2009, 200:916-925.

51. Tang B, Xiao B, Liu Z, Li N, Zhu ED, Li BS, Xie QH, Zhuang Y, Zou QM, Mao XH: Identification of MyD88 as a novel target of miR-155, involved in negative regulation of Helicobacter pylori-induced inflammation. FEBS Lett 2010, 584:1481-1486

52. Ceppi M, Pereira PM, Dunand-Sauthier I, Barras E, Reith W, Santos MA, Pierre P: MicroRNA-155 modulates the interleukin-1 signaling pathway in activated human monocyte-derived dendritic cells. Proc Natl Acad Sci U S A 2009, 106:2735-2740.

53. Androulidaki A, lliopoulos D, Arranz A, Doxaki C, Schworer S, Zacharioudaki V Margioris AN, Tsichlis PN, Tsatsanis C: The kinase Akt1 controls macrophage response to lipopolysaccharide by regulating microRNAs. Immunity 2009, 31:220-231.

54. O'Connell RM, Chaudhuri AA, Rao DS, Baltimore D: Inositol phosphatase SHIP1 is a primary target of miR-155. Proc Natl Acad Sci U S A 2009, 106:7113-7118.

55. Tili E, Michaille JJ, Cimino A, Costinean S, Dumitru CD, Adair B, Fabbri M, Alde H, Liu CG, Calin GA, Croce CM: Modulation of miR-155 and miR-125b levels following lipopolysaccharide/TNF-a stimulation and their possible roles in regulating the response to endotoxin shock. J Immuno/ 2007, 179:5082-5089.

56. Worm J, Stenvang J, Petri A, Frederiksen KS, Obad S, Elmen J, Hedtjarn M, Straarup EM, Hansen JB, Kauppinen S: Silencing of microRNA-155 in mice during acute inflammatory response leads to derepression of c/ebp Beta and down-regulation of G-CSF. Nucleic Acids Res 2009, 37:5784-5792.

57. Nazari-Jahantigh M, Wei Y, Noels H, Akhtar S, Zhou Z, Koenen RR, Heyll K, Gremse F, Kiessling F, Grommes J, Weber C, Schober A: MicroRNA-155 promotes atherosclerosis by repressing $\mathrm{BCl} 6$ in macrophages. $J$ Clin Invest 2012, 122:4190-4202

58. Martinez-Nunez RT, Louafi F, Friedmann PS, Sanchez-Elsner T: MicroRNA-155 modulates the pathogen binding ability of dendritic cells (DCs) by downregulation of DC-specific intercellular adhesion molecule-3 grabbing non-integrin (DC-SIGN). J Biol Chem 2009, 284:16334-16342.

59. Lu C, Huang X, Zhang X, Roensch K, Cao Q, Nakayama Kl, Blazar BR, Zeng Y, Zhou X: miR-221 and miR-155 regulate human dendritic cell development, apoptosis, and IL-12 production through targeting of p27kip1, KPC1, and SOCS-1. Blood 2011, 117:4293-4303.

60. Dunand-Sauthier I, Santiago-Raber ML, Capponi L, Vejnar CE, Schaad O, Irla M, Seguin-Estevez Q, Descombes P, Zdobnov EM, Acha-Orbea H, Reith W: Silencing of c-Fos expression by microRNA-155 is critical for dendritic cell maturation and function. Blood 2011, 117:4490-4500.

61. Turner ML, Schnorfeil FM, Brocker T: MicroRNAs regulate dendritic cell differentiation and function. J Immuno/ 2011, 187:3911-3917.

62. Rodriguez A, Vigorito E, Clare S, Warren MV, Couttet P, Soond DR, van Dongen S, Grocock RJ, Das PP, Miska EA, Vetrie D, Okkenhaug K, Enright AJ, Dougan G, Turner M, Bradley A: Requirement of bic/microRNA-155 for normal immune function. Science 2007, 316:608-611

63. Starczynowski DT, Kuchenbauer F, Argiropoulos B, Sung S, Morin R, Muranyi A, Hirst M, Hogge D, Marra M, Wells RA, Buckstein R, Lam W, Humphries RK, Karsan A: Identification of miR-145 and miR-146a as mediators of the 5q-syndrome phenotype. Nat Med 2010, 16:49-58.

64. Sheedy FJ, Palsson-McDermott E, Hennessy EJ, Martin C, O'Leary JJ, Ruan O Johnson DS, Chen Y, O'Neill LA: Negative regulation of TLR4 via targeting of the proinflammatory tumor suppressor PDCD4 by the microRNA miR-21. Nat Immunol 2010, 11:141-147.

65. Wendlandt EB, Graff JW, Gioannini TL, McCaffrey AP, Wilson ME: The role of MicroRNAs miR-200b and miR-200c in TLR4 signaling and NF-kappaB activation. Innate Immun 2012, 18:846-855

66. Liu X, Zhan Z, Xu L, Ma F, Li D, Guo Z, Li N, Cao X: MicroRNA-148/152 impair innate response and antigen presentation of TLR-triggered dendritic cells by targeting CaMKIla. J Immuno/ 2010, 185:7244-7251.

67. Zhu S, Pan W, Song X, Liu Y, Shao X, Tang Y, Liang D, He D, Wang H, Liu W, Shi Y, Harley JB, Shen N, Qian Y: The microRNA miR-23b suppresses IL-17associated autoimmune inflammation by targeting TAB2, TAB3 and IKKalpha. Nat Med 2012. [Epub ahead of print]

68. Cua DJ, Tato CM: Innate IL-17-producing cells: the sentinels of the immune system. Nat Rev Immunol 2010, 10:479-489.

69. Chen $\mathrm{Q}$, Wang H, Liu Y, Song Y, Lai L, Han Q, Cao X, Wang Q: Inducible microrna-223 down-regulation promotes TLR-triggered IL- 6 and IL-1 $\beta$ production in macrophages by targeting STAT3. PLoS One 2012, 7:e42971. 
70. Bazzoni F, Rossato M, Fabbri M, Gaudiosi D, Mirolo M, Mori L, Tamassia N Mantovani A, Cassatella MA, Locati M: Induction and regulatory function of miR-9 in human monocytes and neutrophils exposed to proinflammatory signals. Proc Natl Acad Sci U S A 2009, 106:5282-5287.

71. Rossato M, Curtale G, Tamassia N, Castellucci M, Mori L, Gasperini S, Mariotti B, De Luca M, Mirolo M, Cassatella MA, Locati M, Bazzoni F: IL-10-induced microRNA-187 negatively regulates TNF-alpha, IL-6, and IL-12p40 production in TLR4-stimulated monocytes. Proc Natl Acad Sci U S A 2012, 109:E3101-E3110.

72. O'Neill LA, Sheedy FJ, McCoy CE: MicroRNAs: the fine-tuners of Toll-like receptor signalling. Nat Rev Immuno/ 2011, 11:163-175.

73. Philippe L, Alsaleh G, Suffert G, Meyer A, Georgel P, Sibilia J, Wachsmann D, Pfeffer S: TLR2 expression is regulated by microRNA miR-19 in rheumatoid fibroblast-like synoviocytes. J Immunol 2012, 188:454-461.

74. Haneklaus M, Gerlic M, Kurowska-Stolarska M, Rainey AA, Pich D, McInnes IB, Hammerschmidt W, O'Neill LA, Masters SL: Cutting Edge: miR-223 and EBV miR-BART15 regulate the NLRP3 inflammasome and IL-1 $\beta$ production. J Immunol 2012, 189:3795-3799.

75. Bauernfeind F, Rieger A, Schildberg FA, Knolle PA, Schmid-Burgk JL, Hornung $\mathrm{V}$ : NLRP3 inflammasome activity is negatively controlled by miR-223. J Immuno/ 2012, 189:4175-4181

76. Sun Y, Varambally S, Maher CA, Cao Q Chockley P, Toubai T, Malter C, Nieves E, Tawara I, Wang Y, Ward PA, Chinnaiyan A, Reddy P: Targeting of microRNA142-3p in dendritic cells regulates endotoxin-induced mortality. Blood 2011, 117:6172-6183.

77. Sharma A, Kumar M, Aich J, Hariharan M, Brahmachari SK, Agrawal A, Ghosh B: Posttranscriptional regulation of interleukin- 10 expression by hsa-miR106a. Proc Natl Acad Sci U S A 2009, 106:5761-5766.

78. Ma F, Xu S, Liu X, Zhang Q, Xu X, Liu M, Hua M, Li N, Yao H, Cao X: The microRNA miR-29 controls innate and adaptive immune responses to intracellular bacterial infection by targeting interferon-gamma. Nat Immunol 2011, 12:861-869.

79. Lodish HF, Zhou B, Liu G, Chen CZ: Micromanagement of the immune system by microRNAs. Nat Rev Immunol 2008, 8:120-130.

80. Lecellier CH, Dunoyer P, Arar K, Lehmann-Che J, Eyquem S, Himber C, Saib A Voinnet O: A cellular microRNA mediates antiviral defense in human cells. Science 2005, 308:557-560

81. Pedersen IM, Cheng G, Wieland S, Volinia S, Croce CM, Chisari FV, David M: Interferon modulation of cellular microRNAs as an antiviral mechanism. Nature 2007, 449:919-922.

82. Stern-Ginossar N, Elefant N, Zimmermann A, Wolf DG, Saleh N, Biton M, Horwitz E, Prokocimer Z, Prichard M, Hahn G, Goldman-Wohl D, Greenfield C, Yagel S, Hengel H, Altuvia Y, Margalit H, Mandelboim O: Host immune system gene targeting by a viral miRNA. Science 2007, 317:376-381.

83. Theofilopoulos AN, Gonzalez-Quintial R, Lawson BR, Koh YT, Stern ME, Kono $\mathrm{DH}$, Beutler B, Baccala R: Sensors of the innate immune system: their link to rheumatic diseases. Nat Rev Rheumatol 2010, 6:146-156.

84. Hall JC, Rosen A: Type I interferons: crucial participants in disease amplification in autoimmunity. Nat Rev Rheumato/ 2010, 6:40-49.

85. Park H, Bourla AB, Kastner DL, Colbert RA, Siegel RM: Lighting the fires within: the cell biology of autoinflammatory diseases. Nat Rev Immunol 2012, 12:570-580.

86. Luo X, Yang W, Ye DQ, Cui H, Zhang Y, Hirankarn N, Qian X, Tang Y, Lau YL, de Vries N, Tak PP, Tsao BP, Shen N: A functional variant in microRNA-146a promoter modulates its expression and confers disease risk for systemic lupus erythematosus. PLOS Genet 2011, 7:e1002128

87. Dai Y, Huang YS, Tang M, Lv TY, Hu CX, Tan YH, Xu ZM, Yin YB: Microarray analysis of microRNA expression in peripheral blood cells of systemic lupus erythematosus patients. Lupus 2007, 16:939-946.

88. Stagakis E, Bertsias G, Verginis P, Nakou M, Hatziapostolou M, Kritikos H, lliopoulos D, Boumpas DT: Identification of novel microRNA signatures linked to human lupus disease activity and pathogenesis: miR-21 regulates aberrant $T$ cell responses through regulation of PDCD4 expression. Ann Rheum Dis 2011, 70:1496-1506.

89. Duroux-Richard I, Jorgensen C, Apparailly F: What do microRNAs mean for rheumatoid arthritis? Arthritis Rheum 2012, 64:11-20.

90. Stanczyk J, Ospelt C, Karouzakis E, Filer A, Raza K, Kolling C, Gay R, Buckley CD, Tak PP, Gay S, Kyburz D: Altered expression of microRNA-203 in rheumatoid arthritis synovial fibroblasts and its role in fibroblast activation. Arthritis Rheum 2011, 63:373-381.

91. Stanczyk J, Pedrioli DM, Brentano F, Sanchez-Pernaute O, Kolling C, Gay RE,
Detmar M, Gay S, Kyburz D: Altered expression of microRNA in synovial fibroblasts and synovial tissue in rheumatoid arthritis. Arthritis Rheum 2008, 58:1001-1009.

92. Kurowska-Stolarska M, Alivernini S, Ballantine LE, Asquith DL, Millar NL, Gilchrist DS, Reilly J, lerna M, Fraser AR, Stolarski B, McSharry C, Hueber AJ, Baxter D, Hunter J, Gay S, Liew FY, Mclnnes IB: MicroRNA-155 as a proinflammatory regulator in clinical and experimental arthritis. Proc Nat Acad SciU SA 2011, 108:11193-11198.

93. Bluml S, Bonelli M, Niederreiter B, Puchner A, Mayr G, Hayer S, Koenders MI, van den Berg WB, Smolen J, Redlich K: Essential role of microRNA-155 in the pathogenesis of autoimmune arthritis in mice. Arthritis Rheum 2011 63:1281-1288.

94. Murata K, Yoshitomi H, Tanida S, Ishikawa M, Nishitani K, Ito H, Nakamura T: Plasma and synovial fluid microRNAs as potential biomarkers of rheumatoid arthritis and osteoarthritis. Arthritis Res Ther 2010, 12:R86.

95. Li YT, Chen SY, Wang CR, Liu MF, Lin CC, Jou IM, Shiau AL, Wu CL: Amelioration of collagen-induced arthritis in mice by lentivirus-mediated silencing of microRNA-223. Arthritis Rheum 2012, 64:3240-3245.

96. Pandis I, Ospelt C, Karagianni N, Denis MC, Reczko M, Camps C, Hatzigeorgiou AG, Ragoussis J, Gay S, Kollias G: Identification of microRNA-221/222 and microRNA-323-3p association with rheumatoid arthritis via predictions using the human tumour necrosis factor transgenic mouse model. Ann Rheum Dis 2012, 71:1716-1723.

97. Nakasa T, Miyaki S, Okubo A, Hashimoto M, Nishida K, Ochi M, Asahara H: Expression of microRNA-146 in rheumatoid arthritis synovial tissue. Arthritis Rheum 2008, 58:1284-1292.

98. Pauley KM, Satoh M, Chan AL, Bubb MR, Reeves WH, Chan EK: Upregulated miR-146a expression in peripheral blood mononuclear cells from rheumatoid arthritis patients. Arthritis Res Ther 2008, 10:R101.

99. Pauley KM, Stewart CM, Gauna AE, Dupre LC, Kuklani R, Chan AL, Pauley BA, Reeves WH, Chan EK, Cha S: Altered miR-146a expression in Sjogren's syndrome and its functional role in innate immunity. Eur J Immuno/ 2011, 41:2029-2039.

100. Zilahi E, Tarr T, Papp G, Griger Z, Sipka S, Zeher M: Increased microRNA-146a/ b, TRAF6 gene and decreased IRAK1 gene expressions in the peripheral mononuclear cells of patients with Sjogren's syndrome. Immunol Lett 2012, 141:165-168.

101. Zhu W, Streicher S, Shen N, Higgs B, Morehouse C, Greenlees L, Amato A Ranade K, Richman L, Fiorentino D, Jallal B, Greenberg S, Yao Y: Genomic signatures characterize leukocyte infiltration in myositis muscles. BMC Genomics 2012, 5:53

102. Honda N, Jinnin M, Kajihara I, Makino T, Makino K, Masuguchi S, Fukushima S, Okamoto Y, Hasegawa M, Fujimoto M, Ihn H: TGF- $\beta$-mediated downregulation of microRNA-196a contributes to the constitutive upregulated type I collagen expression in scleroderma dermal fibroblasts. $\mathrm{J}$ Immunol 2012, 188:3323-3331.

103. Maurer B, Stanczyk J, Jungel A, Akhmetshina A, Trenkmann M, Brock M, Kowal-Bielecka O, Gay RE, Michel BA, Distler JH, Gay S, Distler O: MicroRNA-29, a key regulator of collagen expression in systemic sclerosis. Arthritis Rheum 2010, 62:1733-1743.

104. York MR: Novel insights on the role of the innate immune system in systemic sclerosis. Expert Rev Clin Immunol 2011, 7:481-489.

105. Lehmann SM, Kruger C, Park B, Derkow K, Rosenberger K, Baumgart J, Trimbuch T, Eom G, Hinz M, Kaul D, Habbel P, Kalin R, Franzoni E, Rybak A, Nguyen D, Veh R, Ninnemann O, Peters O, Nitsch R, Heppner FL, Golenbock D, Schott E, Ploegh HL, Wulczyn FG, Lehnardt S: An unconventional role for miRNA: let-7 activates Toll-like receptor 7 and causes neurodegeneration. Nat Neurosci 2012, 15:827-835

106. Fabbri M, Paone A, Calore F, Galli R, Gaudio E, Santhanam R, Lovat F, Fadda P, Mao C, Nuovo GJ, Zanesi N, Crawford M, Ozer GH, Wernicke D, Alder H, Caligiuri MA, Nana-Sinkam P, Perrotti D, Croce CM: MicroRNAs bind to Tolllike receptors to induce prometastatic inflammatory response. Proc Nat Acad SciU SA 2012, 109:E2110-E2116.

107. Gantier MP: New perspectives in MicroRNA regulation of innate immunity. J Interferon Cytokine Res 2010, 30:283-289.

108. Sugatani T, Hruska KA: MicroRNA-223 is a key factor in osteoclast differentiation. J Cell Biochem 2007, 101:996-999.

109. Sugatani T, Hruska KA: Impaired micro-RNA pathways diminish osteoclast differentiation and function. J Bio/ Chem 2009, 284:4667-4678.

110. Sugatani T, Vacher J, Hruska KA: A microRNA expression signature of osteoclastogenesis. Blood 2011, 117:3648-3657. 
111. Nakasa T, Shibuya H, Nagata Y, Niimoto T, Ochi M: The inhibitory effect of microRNA-146a expression on bone destruction in collagen-induced arthritis. Arthritis Rheum 2011, 63:1582-1590.

112. Dorsett $Y$, McBride KM, Jankovic M, Gazumyan A, Thai TH, Robbiani DF, Di Virgilio M, Reina San-Martin B, Heidkamp G, Schwickert TA, Eisenreich T, Rajewsky K, Nussenzweig MC: MicroRNA-155 suppresses activationinduced cytidine deaminase-mediated Myc-Igh translocation. Immunity 2008, 28:630-638.

113. Teng G, Hakimpour P, Landgraf P, Rice A, TuschI T, Casellas R, Papavasiliou FN MicroRNA-155 is a negative regulator of activation-induced cytidine deaminase. Immunity 2008, 28:621-629. doi:10.1186/ar4194

Cite this article as: Luo $X$, et al:: microRNA-mediated regulation of innate immune response in rheumatic diseases. Arthritis Research \& Therapy 2013

15:210. 